\title{
UM OLHAR NA CULPA KAFKIANA
}

\section{Claudio César Montoto ${ }^{(*)}$}

O objetivo do presente trabalho é refletir sobre o complexo de culpa em uma obra do escritor Franz Kafka. Trata-se de Carta ao pai, uma epístola escrita com a intenção de ser entregue ao progenitor, Hermann Kafka, mas que nunca chegou até suas mãos. Do mesmo modo que uma grande parte da produção literária de Kafka, essa obra foi publicada após a morte do romancista e graças ao amigo Max Brod. Daí que o título, escolhido por Brod, denote um distanciamento da autoria -"ao pai"- e não, como poderia ser mais adequado, um "ao meu pai". É provável que o êxito que ainda hoje tem essa obra deva-se ao fato de que nela o autor manifesta, como causa de sua carreira de escritor, a relação terrivelmente controversa com o pai:

Meus escritos tratavam de você, neles eu expus as queixas que não podia fazer no seu peito. Eram uma despedida intencionalmente prolongada de você; só que ela, apesar de imposta por você, corria na direção definida por mim (1997, p.52).

Pelo fato de abranger duas áreas de conhecimento, a literatura e a psicanálise, consideramos válidos alguns esclarecimentos para evitar sermos tomados por reducionistas. Não temos a intenção de instituir uma das áreas em um posicionamento superior à outra, e sim de dialogar, de interpelar ambas para realizar um diálogo mais frutífero. Da área de psicanálise, não faremos nenhuma tentativa de diagnóstico, por considerarmos que essa é a causa de tantos fracassos da psicanálise aplicada. O fenômeno clínico é insubstituível, único e se for considerado importante diagnosticar, essa ação deverá ser realizada unicamente dentro do marco da clínica psicanalítica. É claro que muitas citações que faremos, neste ensaio, falam de elementos que identificam um proceder acorde com a neurose obsessiva ou com a melancolia. Mas, estamos muito longe de pretender uma leitura tão

(*) Doutor em Semiótica, psicanalista, tradutor especializado em psicanálise, professor assistente doutor do Departamento de Linguística da Pontifícia Universidade Católica de São Paulo (PUC-SP). 
redutora como a que se dedica a diagnosticar um comportamento neurótico ou obsessivo no narrador ou em uma personagem.

É significativo que uma carta de ordem pessoal e íntima do ser humano tenha sido muito difundida, aceita e consagrada como uma grande obra literária. Não obstante isso, o fenômeno da escrita passa por um processo que de nenhuma maneira pode ser igualado ao ato clínico.

Entretanto, fazemos eco das palavras de Rand \& Torok (1997, p. 35) que sustentam que:

[...] a literatura aporta alguma coisa imprevista, faz amadurecer o instrumento analítico e enriquece por sua singularidade as possibilidades de escuta. No intercâmbio que fazemos entre a literatura e a teoria analítica, o privilégio corresponde, indefectivelmente, ao texto. O encontro entre ambas dará lugar a incessantes modificações teóricas e não mais a confirmações e sim a conformações. Em lugar de adaptar o texto para a psicanálise, a psicanálise adaptar-se-á ao texto literário. Onde a clínica não deu (ou ainda não deu) um perfeito exemplo para a intuição freudiana, a literatura poderia estar chamada a fazê-lo.

No presente ensaio vamos falar de "sentimento de culpa" e aão deve ser confundido com "remorso", termo este próprio de áreas :omo a moral e a ética. Não se trata de uma sensação que é um efeito imediato de um juízo moral interno sobre um ato cometido ou a omissão dele e sim de um processo que, de maneira inconsciente, toma conta de um ser e limita ou determina sua forma de ver o mundo e de posicionar-se frente aos outros semelhantes. Talvez seja de interesse lembrar que o termo "schuld" e o epíteto "schuldig" (Kaufmann, 1996: 104), em língua alemã, utilizados por Freud para analisar o "sentimento de culpa" signifiquem, ao mesmo tempo, "culpado" e "devedor". Ou seja, que o conceito de falta, tanto de alguma coisa faltante quanto de uma infração cometida, mesmo imaginariamente, sempre está denotado com ambos os vocábulos e é de fundamental importância na compreensão da carta kafkiana.

Por isso, não haveria melhor síntese, ao falar da Carta ao pai, que dizer que ela trata do sentimento de culpa inconsciente e da falta. Falta de reconhecimento por parte da figura paterna, da alteridade; falta de desprendimento do outro por uma identificação maciça na 
falta do outro; falta de liberdade para escolher e falta como infração por não atingir o que o Ideal do Eu estabeleceu como modelo a ser seguido. Mas, adentremo-nos no estudo kafkiano com umas reflexões psicanalíticas prévias.

Muito embora já manifestamos a intenção de não diagnosticar, consideramos importante citar o artigo "Complejo fraterno y complejo de Edipo en la obra de Frank Kafka" do psicanalista argentino Luis Kancyper (1998, p.329), porque nos pode servir como provocação para uma tentativa de achar "os restos arqueológicos do Inconsciente" - diria Freud - na obra literária. O autor manifesta a hipótese de que, no texto kafkiano, há marcas denotativas que demonstram que "o complexo paterno kafkiano esteve condicionado e reforçado por sobreinvestimentos ominosos originários de uma masoquista elaboração culpógena no pequeno Franz devida aos lutos patológicos pelas mortes precoces de seus irmãos homens que, como duplos consangüíneos ominosos, o perseguiam e incriminavam, projetando essas incriminações fraternas na figura do pai".

Há uma citação textual de Kafka que pode sustentar essa hipótese:

Mas justo como pai você era forte demais para mim, principalmente porque meus irmãos morreram pequenos, minhas irmãs só vieram muito tempo depois e eu tive, portanto, de suportar inteiramente só o primeiro golpe, e para isso eu era fraco demais (1997, p.10).

A idéia latente de aniquilamento vê-se reforçada logo depois quando afirma que “ (...) éramos tão diferentes e nessa diferença tão perigosos um para o outro, que se alguém por acaso quisesse calcular antecipadamente como eu, a criança que se desenvolvia devagar, e você, o homem feito, se comportariam um com o outro, poderia supor que você simplesmente me esmagaria sob os pés e que não sobraria nada de mim. Ora, isso não aconteceu - o que é vivo não comporta cálculo - mas talvez tenha acontecido algo pior"1 (1997, p.11).

O que pode acontecer, na vida de um ser humano, mais terrível que ser esmagado? Pareceria que a morte houvesse sido uma saída muito melhor para o sofrimento que estar 'condenado' a viver com um sentimento ominoso pelo resto da vida biológica. Esta dor

\footnotetext{
I O sublinhado é nosso.
} 
psíquica, implícita na citação, acompanhou sempre a vida do homemescritor e daria uma chave de leitura para refletir sobre os sintomas físicos, no real do corpo, isto é, as doenças que o homem Kafka desenvolveu ao longo da sua existência.

Mais tarde, volta a aparecer a figura terrível de aniquilamento: "Já estava esmagado pela simples materialidade do seu corpo" (1997, p.14).

O paradoxo é evidente porque, num primeiro momento, nega que tenha acontecido o "esmagamento" e levanta a hipótese de que quiçá aconteceu "algo pior". Mas, logo reconhece que sim, existiu o esmagamento realizado pelo pai. Usando a teoria de Arnaldo Rascovsky (1974), podemos afirmar que essa queixa pode ser rotulada como denúncia de filicídio. $O$ texto anuncia que pode ter acontecido alguma coisa pior que ser esmagado na corporeidade. Poderia estar mencionando uma atitude perversa de esmagar a vida psíquica da vítima -o filho - e deixá-lo vivo - em termos biológicos - para penar com essa miséria?

Esmaga-se para destruir o que se tem ou para impedir que o outro seja exatamente isso, um outro?

Entretanto, a nossa intenção é citar textualmente trechos nos quais o sentimento de culpa aparece de maneira evidente e logo fazer algumas reflexões. O significante "culpa" está constantemente citado ao longo da carta.

Kancyper (1998, p.339) sublinha a constante presença do termo 'culpa' nessa obra e após um levantamento desse vocábulo, na edição em língua espanhola, detectou trinta e cinco vezes a palavra
"culpabilidade".

Mas, em se tratando de um vocábulo polissêmico, como poderia ser feito um recorte epistemológico congruente que
possibilitasse uma reflexão sobre ele?

Consideramos de suma utilidade as articulações sobre a culpa realizadas por Hugo Bleichmar (1983) em seu livro Depressão. Um estudo psicanalítico. O autor emite críticas à leitura kleiniana da culpa por considerá-la insuficiente. Manifesta que a intencionalidade 
agressiva $^{2}$ não ocorre só "num nível corporal, concreto", isto é, não pode ser sustentado que "sempre que há culpa num indivíduo é porque previamente tem que ter existido agressão real ou fantasiada" (1983, p.64).

As hipóteses fundamentais de Bleichmar são de que alguém pode sentir-se culpado não pelo que fez ou fantasiou, senão pela:

a) identificação com a imagem que outro lhe dá de si mesmo e na qual aparece como culpado, e

b) identificação com um outro que se sente culpado.

Ou seja, que a culpa também pode ser devida a uma autoagressão, isto é, à relação de ódio consigo mesmo como a interiorização de uma relação intersubjetiva. Pode ser quando, fazendo uso do sofrimento, procura-se o amor do outro ou do superego. Dessa maneira o fato de sofrer atua como sacrifício ritual, como propiciação porque não há intenção de provocar o sofrimento em si mesmo, mas o amor do outro.

Entre nós não houve propriamente uma luta; fui logo liquidado; o que restou foi fuga, amargura, luto, luta interior (1997, p.40).

Essa frase poderia ser interpretada como tentativa de amaciar a vontade do pai? Não podemos esquecer que o motivo que originou a epístola foi a tentativa de convencer o pai de que aceitasse 0 casamento de Franz Kafka. Mais adiante analisaremos o tema da possibilidade /impossibilidade para o casamento.

Mas, completando o exemplo a) e este é muito importante para refletir sobre o texto kafkiano, a culpa pode aparecer quando "um personagem significativo vê a criança como má, seja dito explicitamente ou transmitido através das mil formas sutis em que se pode induzir inconscientemente em outro uma determinada imagem

2 Segundo Bleichmar, entende-se por agressão a intencionalidade de provocar dano ou sofrimento, seja físico ou moral, pelo prazer que isso implica (1983, p.58). E logo completa, "A auto-agressão é, para a intencionalidade agressiva o que o narcisismo é para o amor" porque considera também a possibilidade de uma agressão dirigida contra o próprio sujeito. 
de si", e assim "a criança se representará a si mesma como má independentemente de suas condutas ou fantasias"'(1983, p.64). ${ }^{3}$

No caso da Carta ao pai poderemos apreciar que há passagens em que o narrador expressa a culpa "inculcada" pelas atitudes do pai, e noutras a relação intersubjetiva faz com que o narrador exima de culpa o pai e se autocastigue, quiçá como uma tentativa de solicitar o amor do outro.

Um exemplo disso seria a seguinte frase:

(...) sentia-me miserável e na realidade não só diante de você, mas do mundo inteiro, pois para mim você era a medida de todas as coisas": "Da sua poltrona você regia o mundo: Sua opinião era certa, todas as outras disparatadas, extravagantes, anormais. Tão grande era sua auto-confiança que você não precisava de modo algum ser conseqüente... (1997, p.14-15).

Talvez poderia ser lido da seguinte maneira: se o pai encarnava o eu-ideal, fracassava a tentativa de corresponder às expectativas paternas, mas se existia uma total identificação com o pai, considerava o seu progenitor como miserável e, pelo fato de ser o pai "a medida de todas as coisas", o narrador se autopunia com o sentimento de culpa por ambos serem uns fracassados.

Para mim você não era uma coisa bizarra, eu não podia escolher, tinha de levar tudo" (1997, p.20). "(...) logo cedo você me interditou a palavra (1997, p.21).

A respeito do sentimento de culpa é bom lembrar que Freud, no ensaio "O ego e o id" (vol. XIX, ESB, p. 63), numa nota ao pé de página, no capítulo $\mathrm{V}$, manifesta que:

A luta com o obstáculo de um sentimento inconsciente de culpa não é fácil para o analista. Nada pode ser feito contra ele diretamente, e também nada indiretamente, exceto o lento processo de descobrir as raízes reprimidas inconscientes e assim, gradativamente, transformá-lo num sentimento consciente de culpa. Tem-se uma oportunidade especial para influenciá-lo quando esse sentimento de culpa Ics. é 'emprestado' -

Sublinhado no original. 
quando é produto de uma identificação com alguma outra pessoa que foi outrora objeto de uma catexia erótica. Um sentimento de culpa que foi dessa maneira adotado freqüentemente constitui o único traço remanescente da relação amorosa abandonada e de modo algum é fácil de reconhecer como tal.

Chama a atenção o fato de que apenas começa a carta, o narrador expressa que tanto ele quanto seu pai estão isentos de responsabilidade pelo mútuo distanciamento - lógico, de acordo com a visão do narrador.

(...) E de fato você me recrimina por isso como se fosse culpa minha, como se por acaso eu tivesse podido, com uma virada do volante, conduzir tudo para outra direção, ao passo que você não tem a mínima culpa, a não ser talvez o fato de ter sido bom demais para mim (1997, p.8).

Até aqui esse trecho pode ser interpretado como permeado por um sentimento de ironia, mas, vejamos como segue:

Esse seu modo usual de ver as coisas eu só considero justo na medida em que também acredito que você não tem a menor culpa pelo nosso distanciamento. Mas eu também não tenho a menor culpa (1997, p.8).

Não obstante isso, logo depois o narrador declara que “(...) é bem possível que, mesmo que tivesse crescido totalmente livre da sua influência, eu não pudesse me tornar um ser humano na medida de seu coração" (1997, p.9).

Como pode ser analisada essa frase?

a) Cresceu totalmente influenciado pelo pai,

b) Não é um ser humano na medida do coração do pai.

Logo depois, volta a eximir o pai da culpa: "nem de longe acredito numa culpa da sua parte". Mas continua: "Você influiu sobre mim como tinha de influir, só que precisa deixar de considerar como uma maldade especial da minha parte o fato de eu ter sucumbido a essa influência" (1997, p.11). ${ }^{4}$

\footnotetext{
${ }^{4}$ O sublinhado é nosso.
} 
Essa frase pode ser articulada com a seguinte: “ (...) eu hoje só tremo menos que na infância porque o sentimento de culpa exclusivo da criança foi em parte substituído pela compreensão do nosso comum desamparo" (1997, p.21).

Vejamos uma enumeração de atitudes do pai:

Seus recursos oratórios extremamente eficazes e que nunca falhavam, pelo menos comigo, eram: insulto, ameaça, ironia, riso malévolo e - curiosamente - auto-acusação" (1997, p.23). As duas hipóteses de Hugo Bleichmar, antes mencionadas, podem servir como articulação com essa frase kafkiana.

É interessante ver que a frase enuncia como recursos "oratórios" as agressões do pai "filicida" e os termos "oratória", oralidade, oral, podem ser articulados com alguns dos sintomas que aparecem, textualmente, na carta. Por exemplo:

\section{Gagueira}

Na sua presença -quando se trata das suas coisas você é um excelente orador - adquiri um modo de falar entrecortado, gaguejante" (1997, p.22).

Hipocondria

(...) assim ficou aberto o caminho para toda hipocondria (1997, p.54).

\section{Tuberculose}

(...) até que, com o esforço sobre-humano de querer casar (vou ainda falar sobre isso), o sangue me saiu dos pulmões... (1997, p.54).

A tuberculose sofrida pelo escritor o levou à tumba vários anos após ter escrito este texto analisado.

Mas, talvez o exemplo mais forte da exteriorização somática de um conflito interior possa estar no seguinte trecho:

(...) Mais uma vez que eu não estava seguro de coisa alguma; como precisava obter de cada instante uma confirmação da minha presença e não possuía nada de um modo próprio, indubitável, exclusivo, decidido apenas por mim - um filho deserdado, na verdade, era natural que até a coisa mais próxima, o próprio corpo, se tornasse incerto para mim (1997, p.54). 
Ele é incapaz de perceber a sua própria corporeidade; sente-se como alheio, intruso no seu próprio ser ou, melhor ainda: uma propriedade de outro. Filho deserdado de qualquer sentimento de alteridade, preso, colado ao desejo do outro: o pai. Por isso, podemos pensar que estava deserdado do poder de reconhecer-se como um outro independente. No começo da carta, quando fala do medo, o autor expressa a característica de inominado desse medo que vai além do poder evocativo da memória. Disse:

(...) o medo e suas conseqüências me inibem diante de você e porque a magnitude do assunto [medo] ultrapassa de longe a minha memória e meu entendimento (1997, p.7).

A memória e seu poder evocativo e o entendimento, ou seja, a capacidade de raciocínio não alcançam para dar conta, no simbólico, do medo que sente o filho pelo pai. Mas, lembrando o trabalho de Ivanise Fontes (2002), especialmente a leitura que faz da obra de Ferenczi, sabemos que o corpo guarda a memória do pré-verbal, aquilo que não pôde ser inscrito no simbólico da linguagem, mas que é sempre 'transportado' até aparecerem as oportunidades de vir à tona. Os sintomas físicos podem ser manifestações simbólicas, no real do corpo, desse inominado que precede à memória e ao entendimento.

A respeito dessas doenças e da própria confissão de "hipocondríaco", é conveniente lembrar que Freud, no ensaio "A questão leiga", que consta no volume XX das Obras completas, menciona que o superego - dos neuróticos - se confronta com o ego como um pai rigoroso se defronta com um filho: e a moralidade deles atua de modo primitivo porque o ego é punido pelo superego. As doenças servem como instrumentos para realizar a autopunição e os neuróticos têm de comportar-se como se fossem governados por um sentimento de culpa que, para ser satisfeito, precisa ser punido mediante as doenças.

Muito embora o conteúdo da carta trate de maneira exclusiva do pai, comprovamos que a figura materna também é analisada por Kafka (1997, p.29; 36-42).

Em longos trechos são mencionadas as figuras parentais configurando o triângulo com o narrador. A mãe está isenta de críticas? De jeito nenhum, porque detrás do discurso manifesto é 
evidente que há um reproche por tê-lo abandonado na força esmagadora do pai.

A mãe é representada como uma figura tão fraca que escolhe abandonar a sua função materna, nesse caso de equilíbrio por oposição à vontade do pai, e deixar Kakfa à mercê da violência do pai. Esse comodismo destrói a única esperança de achar sustento para não sucumbir perante o pai filicida. Alguém já escutou a argumentação de uma mãe: "Você vai ver quando seu pai chegar!!"?

Nas últimas páginas da carta aparecem as reflexões sobre o casamento. Novamente estamos em presença de um paradoxo porque se, como dizem os críticos, a carta foi escrita para defender a decisão de casar, ao mesmo tempo manifesta a impossibilidade de chegar a fazê-lo por estar condenado ao fracasso.

Kafka (1997, p.66 e ss.) manifesta que o casamento, com total certeza, seria a garantia para se libertar da família e obter independência. Mas ele reconhece que "desde o ponto de vista espiritual" é manifestamente incapaz de se casar. Enuncia as razões: pressão generalizada do medo, fraqueza e autodesprezo. Logo, tenta explicar melhor essas características e menciona que se ele se cassasse seria igual ao pai. A partir desse trecho (p. 67) podemos apreciar como aparece, de maneira evidente, o complexo de Edipo. Vejamos:

Se eu quiser me tornar independente, na relação especial de infelicidade em que me encontro com você, preciso fazer alguma coisa que não tenha a menor ligação possível com a sua pessoa; o casamento é sem dúvida o que há de maior, e confere a autonomia mais honrosa; mas também está, ao mesmo tempo, na mais estreita vinculação com você. Por esse motivo, querer sair daí tem algo de delirante, e qualquer tentativa é quase punida com a loucura (1997, p.67).

Pensamos que, ao expressar "assim como somos, porém, o casamento me está vedado pelo fato de que ele é precisamente o seu domínio mais próprio" (p. 68) e logo analisar o casamento dos pais, o narrador está numa posição inconsciente de ocupar o lugar do pai. Se Kafka se casasse - fato que na vida real nunca aconteceu - estaria cometendo incesto com a própria mãe simplesmente por ocupar o lugar do pai... e isso, como ele mesmo diz, seria punido com a loucura. 
Freud nos esclarece esse ponto no seu ensaio "Dostoievski e o parricídio" (1928,[1927],1996,Volume:XXI; ESB. p. 188-189):

O relacionamento de um menino com o pai é, como dizemos, 'ambivalente'. Além do ódio com que procura livrar-se do pai como rival, uma certa medida de ternura por ele também está habitualmente presente. As duas atitudes mentais se combinam para produzir a identificação com o pai; o menino deseja estar no lugar do pai porque o admira e quer ser como ele, e também por desejar colocá-lo fora do caminho. Todo esse desenvolvimento se defronta com um poderoso obstáculo. Em determinado momento, a criança vem a compreender que a tentativa de afastar o pai como rival seria punida por ele com a castração. Assim, pelo temor à castração - isto é, no interesse de preservar sua masculinidade - abandona seu desejo de possuir a mãe e livrar-se do pai. $\mathrm{Na}$ medida em que esse desejo permanece no inconsciente, constitui a base do sentimento de culpa.

Fica claro, ao analisarmos essa longa citação, que o sentimento de culpa está estreitamente vinculado com o Complexo de Édipo. O pai da psicanálise na sua obra completa redigiu, pelo menos, 91 longos trechos sobre o "sentimento de culpa" e em muitos deles menciona a fundamental importância que têm o mito da horda primitiva e o assassinato do pai como causas fundamentais para se instalar o sentimento de culpa. A tudo isso, devemos acrescentar as reflexões sobre o conflito entre o superego e o ego e a consequiente ação do mundo da Cultura. Sabemos que a constituição do superego articula-se com a imagem paterna introjetada na criança, a qual adquire estatuto de lei. No ensaio sobre Dostoievski, já mencionado, podemos ver que Freud sustenta que quando um pai é muito severo, essa característica será transladada para o superego.

Vejamos, a título de exemplo ilustrativo, uma das tantas citações (1933 [1932], ESB, Volume XXII, 1996, p.63/84) em que Freud menciona o conflito instituído entre o superego e o ego:

O superego aplica o mais rígido padrão de moral ao ego indefeso que the fica à mercê; representa, em geral, as exigências da moralidade, e compreendemos imediatamente que nosso sentimento moral de culpa é expressão da tensão entre o ego e o superego. 
Conferência XXXI, A dissecção da personalidade psíquica.

Assim como dizemos, nos primeiros momentos da constituição do sujeito, que um ser está tomado pela pulsão, poderíamos parafrasear e manifestar que no sentimento de culpa kafkiano a personagem está tomada pelo supereu. A citação freudiana nos faz lembrar do livro "Grande Ética" de Aristóteles que, ao tratar de virtudes, as define como o ponto médio entre a carência [a falta] e o excesso. Pareceria que a força desproporcional em prol da potestade do supereu é a causa primordial da constante presença do sentimento de culpa.

Entretanto, poderíamos questionar, como achar um instrumento de mensura para definir uma quantidade, uma estatística ou uma medida eqüidistante entre a falta e o excesso? Lógico que não há, e tampouco seria de aplicação se existisse, porque sempre nos defrontamos com o mito pessoal de cada ser humano, único e impossível de generalizar. Como disse Freud, em "O mal-estar na civilização" (ESB, 1930 [1929] volume XXI), a coisa decisiva não é o fato de matar ou não o pai -da horda primitiva - porque todos, de algum modo e pelo fato de pertencermos à Cultura, estamos condenados a sentir culpa.

\section{REFERÊNCIAS BIBLIOGRÁFICAS}

BLEICHMAR, Hugo. Depressão, um estudo psicanalítico. Porto Alegre: Artes Médicas, 1983.

FONTES, Ivanise. Memória corporal e transferência: fundamentos para uma psicanálise do sensível. São Paulo: Via Lettera., 2002.

FREUD, Sigmund. O ego e o id. [1923]. Obras completas. ESB. Volume XIX. Rio de Janeiro: Imago, 1996, p. 15-82.

FREUD, Sigmund. "El 'Yo' y el 'Ello'". [1923]. Obras Completas. Volume 15. Buenos Aires: Hyspamérica Ediciones Argentina S.A., 1993, p. 2701-2728. 
FREUD, Sigmund. A questão da análise leiga; Um estudo autobiográfico. [1926]. Obras completas, ESB, volume XX, Rio de Janeiro: Imago, 1996, p.173-240.

FREUD, Sigmund. Dostoievski e o parricídio; O futuro de uma ilusão. [1928]. Obras completas. ESB, volume XXI, Rio de Janeiro: Imago, 1996, p.179-198.

FREUD, Sigmund. "Conferencia XXXI, A dissecção da personalidade psíquica. Novas conferências introdutórias sobre Psicanálise”. [1932]. Obras completas, Volume XXII, Rio de Janeiro: Imago, 1996, p. 63/84.

KAFKA, Franz. Carta ao pai. Tradução e posfácio de Modesto Carone. São Paulo: Companhia das Letras, 1997.

KANCYPER, Luis. Complejo fraterno y complejo de Edipo en la obra de Franz Kafka. Revista de Psicoanálisis. Buenos Aires, T. LV, n. 2, p. 325-51, 1998.

KAUFMANN, Pierre. Dicionário enciclopédico de Psicanálise. O legado de Freud a Lacan. Rio de Janeiro: Jorge Zahar, 1996.

RAND, N. \& TOROK, M. El psiquismo ante las generaciones. Buenos Aires: Editorial Amorrortu, 1997. La inquietante extrañeza de Freud ante el hombre de arena. 